\title{
Impact of Obesity on the Metabolic Control of Type 2 Diabetes: Results of the Turkish Nationwide Survey of Glycemic and Other Metabolic Parameters of Patients with Diabetes Mellitus (TEMD Obesity Study)
}

\author{
Alper Sonmez $^{a} \quad$ Volkan Yumuk $^{b}$ Cem Haymana ${ }^{a} \quad$ Ibrahim Demirci $^{a}$ \\ Cem Barcin $^{c}$ Sinem Kıyıcı ${ }^{d}$ Sibel Güldikene Gonca Örük ${ }^{f}$ \\ Basak Ozgen Saydam $^{g}$ Süleyman Baldane ${ }^{\text {h }}$ Faruk Kutlutürk $^{\mathrm{i}}$ \\ Ferit Kerim Küçüklerj Oğuzhan Deynelik Berrin Çetinarslan' \\ Tevfik Sabuncu $^{m}$ Fahri Bayram ${ }^{n}$ Ilhan Satman ${ }^{\circ}$ TEMD Study Group
}

\begin{abstract}
aDepartment of Endocrinology and Metabolism, Gulhane School of Medicine, University of Health Sciences, Ankara, Turkey; ${ }^{b}$ Department of Endocrinology and Metabolism, Cerrahpasa Medical Faculty, Istanbul University, Istanbul, Turkey; ' Department of Cardiology, Gulhane School of Medicine, University of Health Sciences, Ankara, Turkey; ${ }^{d}$ Department of Endocrinology and Metabolism, Bursa Yuksek Ihtisas Training and Research Hospital, University

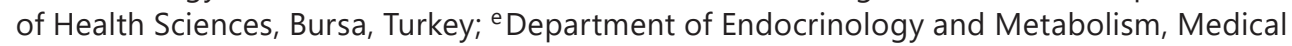

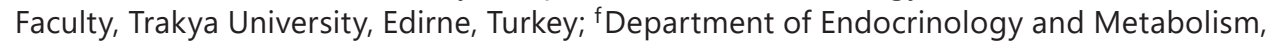
Atatürk Education and Research Hospital, Izmir Katip Celebi University, Izmir, Turkey; gDepartment of Endocrinology and Metabolism, Medical Faculty, Dokuz Eylül University, Izmir, Turkey; ${ }^{\text {h}}$ Department of Endocrinology and Metabolism, Medical Faculty, Selçuk University, Konya, Turkey; 'Department of Endocrinology and Metabolism, Medical Faculty, Gaziosmanpaşa University, Tokat, Turkey; ${ }^{j}$ Department of Endocrinology and Metabolism, Medical Faculty, Hitit

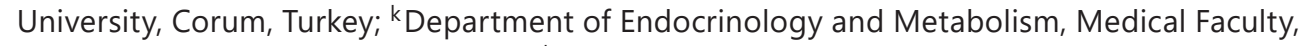
Marmara University, Istanbul, Turkey; 'Department of Endocrinology and Metabolism, Medical Faculty, Kocaeli University, Kocaeli, Turkey; 'mepartment of Endocrinology and Metabolism, Medical Faculty, Harran University, Urfa, Turkey; ${ }^{\text {n} D e p a r t m e n t ~ o f ~ E n d o c r i n o l o g y ~ a n d ~}$ Metabolism, Medical Faculty, Erciyes University, Kayseri, Turkey; ${ }^{\circ}$ Department of Endocrinology and Metabolism, Medical Faculty, Istanbul University, Istanbul, Turkey
\end{abstract}

Collaborators of the TEMD Obesity Study Group are listed in the online supplementary material. 
Sonmez et al.: Obesity and the Metabolic Control of Type 2 Diabetes: TEMD Obesity Study

\title{
Keywords
}

Obesity $\cdot$ Type 2 diabetes $\cdot$ HbA1C $\cdot$ Blood pressure $\cdot$ Lipid metabolism

\begin{abstract}
Background: Obesity is the main obstacle for metabolic control in patients with type 2 diabetes. Turkey has the highest prevalence of obesity and type 2 diabetes in Europe. The effect of obesity on the metabolic control, and the macro- and microvascular complications of patients are not apparent. Objectives: This nationwide survey aimed to investigate the prevalence of overweight and obesity among patients with type 2 diabetes and to search for the impact of obesity on the metabolic control of these patients. We also investigated the independent associates of obesity in patients with type 2 diabetes. Methods: We consecutively enrolled patients who were under follow-up for at least 1 year in 69 tertiary healthcare units in 37 cities. The demographic, anthropometric, and clinical data including medications were recorded. Patients were excluded if they were pregnant, younger than 18 years, had decompensated liver disease, psychiatric disorders interfering with cognition or compliance, had bariatric surgery, or were undergoing renal replacement therapy. Results: Only $10 \%$ of patients with type 2 diabetes $(n=4,648)$ had normal body mass indexes (BMI), while the others were affected by overweight (31\%) or obesity (59\%). Women had a significantly higher prevalence of obesity (53.4 vs. $40 \%)$ and severe obesity (16.6 vs. 3.3\%). Significant associations were present between high BMI levels and lower education levels, intake of insulin, antihypertensives and statins, poor metabolic control, or the presence of microvascular complications. Age, gender, level of education, smoking, and physical inactivity were the independent associates of obesity in patients with type 2 diabetes. Conclusion: The TEMD Obesity Study shows that obesity is a major determinant of the poor metabolic control in patients with type 2 diabetes. These results underline the importance of prevention and management of obesity to improve health care in patients with type 2 diabetes. Also, the results point out the independent sociodemographic and clinical associates of obesity, which should be the prior targets to overcome, in the national fight with obesity.
\end{abstract}

(C) 2019 The Author(s)

Published by S. Karger AG, Basel

\section{Introduction}

Overweight and obesity is a pandemic that plays a major role in the pathogenesis of type 2 diabetes and a multitude of its complications [1-3]. The upsurge in obesity rates appears to be the primary factor for the recent increase in the prevalence of type 2 diabetes $[4,5]$. Several medications commonly used for the treatment of diabetes or its complications also increase adiposity and augment this vicious cycle [6-8]. Obesity is also a significant hurdle in diabetes management and an independent risk factor for cardiovascular diseases $[4,9]$. The prevalence of obesity varies in different regions of the world and there is hardly enough data about the effects of obesity on the achievement of metabolic targets in patients with type 2 diabetes [10].

The TEMD Obesity Study (Turkish Nationwide Survey of Glycemic and Other Metabolic Parameters of Patients with Diabetes Mellitus) was designed to investigate the sociodemographic characteristics and the cardiometabolic risk status of Turkish adults with diabetes mellitus [11]. The present TEMD Obesity Study specifically investigates these patients to find out the prevalence of overweight and obesity among patients with type 2 diabetes. The study also assesses the relationship between obesity and the major cardiometabolic risk factors, macro- and microvascular complications, and sociodemographic, clinical, and self-management factors. Finally, the TEMD Obesity Study looks for the independent associates of obesity in a population with type 2 diabetes. 
Sonmez et al.: Obesity and the Metabolic Control of Type 2 Diabetes: TEMD Obesity Study

\section{Methods}

The TEMD Obesity Study is a cross-sectional, nationwide, multicenter survey, which was carried out between April 1 and June 30, 2017 in 68 tertiary endocrine units from 37 cities throughout Turkey. The study centers were selected according to the 12 Nomenclature of Territorial Units for Statistics (NUTS) regions of the country. Both local and central ethics committees approved the study. The ClinicalTrials.gov registration number is NCT03455101. All patients signed informed consent forms prior to data collection. The study protocol is given in detail elsewhere [11].

Patients with either type 1 or 2 diabetes who were under follow-up in the same center for at least 1 year were consecutively enrolled in the original study [11]. The present report is prepared only for the patients with type 2 diabetes. Patients were excluded if they were pregnant, younger than 18 years, had decompensated liver disease, psychiatric disorders interfering with cognition or compliance, had bariatric surgery, or were undergoing renal replacement therapy. A total of 4,756 patients with type 2 diabetes were registered. Cases without body mass index (BMI) records $(n=108)$ were excluded, and data from 4,648 patients were evaluated in this report.

Patients were asked to fill specifically designed questionnaires about sociodemographic characteristics (age, marital status, education, occupation, and income), concomitant diseases, medications, macro- and microvascular complications, family history, lifestyle and personal diabetes management (diet, exercise, smoking, self-monitoring of blood glucose, and frequency of hypoglycemia), data of outpatient care standards (dietitian visits, diabetes nurse interviews, foot and dental examinations, and vaccinations), treatment regimens, and current and previous laboratory data.

\section{Anthropometrics}

The height, weight, and waist circumference recordings were performed according to the standard protocol with the patients in their underwear. The ratio of weight to the square of height $\left(\mathrm{kg} / \mathrm{m}^{2}\right)$ was given as BMI. Arterial blood pressure (ABP) was recorded using automatic blood pressure (BP) monitors (Omron M2, HEM-7121-E) in a sitting position after at least 5 min of rest. Three consecutive measurements were conducted on the same arm, and the mean was recorded. We asked patients to measure ABP at home twice a day for a week. The mean of these recordings was also recorded during their control visit.

\section{Laboratory Analysis}

Laboratory evaluations were performed in the local hospitals where the interviews were conducted. For biochemical analyses, all blood samples were collected from the antecubital vein between 08:00 and 10:00 after an overnight fast. All laboratory parameters were measured using standard procedures. The levels of glucose, total and high-density lipoprotein cholesterol (HDL-C), and triglycerides (TG) were measured enzymatically. LDL-C was calculated using Friedewald's equation (LDL-C = total cholesterol - [HDL-C + TG/5]) if TG was less than $400 \mathrm{mg} / \mathrm{dL}$ [12]. Glycated hemoglobin (HbA1c) was measured through high-performance liquid chromatography, turbidimetric inhibition immunoassay, or enzymatic methods. Estimated glomerular filtration rate (eGFR) was calculated by the Chronic Kidney Disease Epidemiology Collaboration (CKD-EPI) formula.

\section{Definitions}

Hypertension was the presence of home BP recordings $>135 / 85 \mathrm{~mm} \mathrm{Hg}$ or currently undergoing antihypertensive treatment. For patients who were not able to record their BP at 


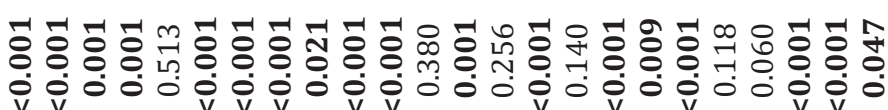

Sonmez et al.: Obesity and the Metabolic Control of Type 2 Diabetes: TEMD Obesity Study

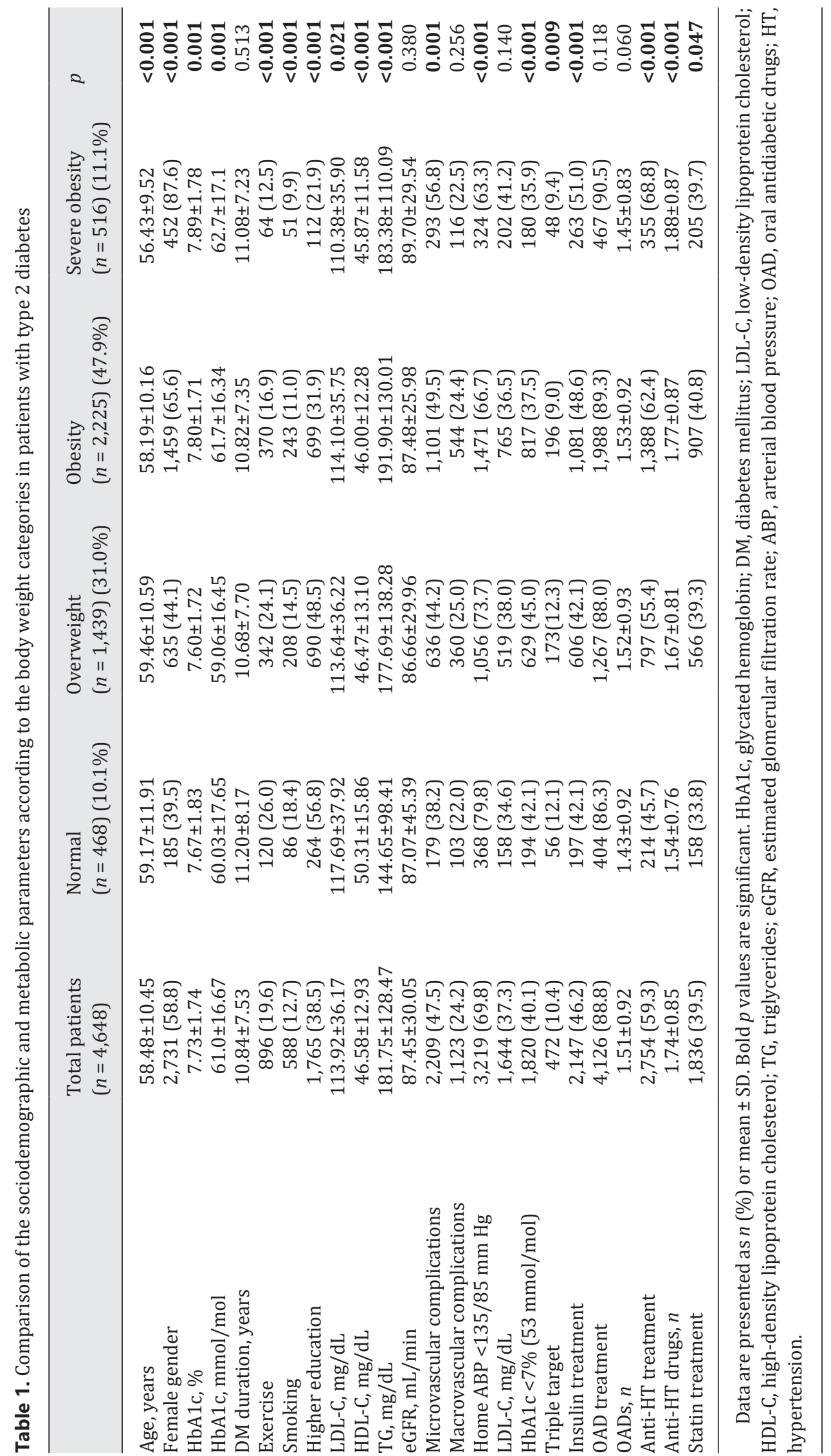


Sonmez et al.: Obesity and the Metabolic Control of Type 2 Diabetes: TEMD Obesity Study

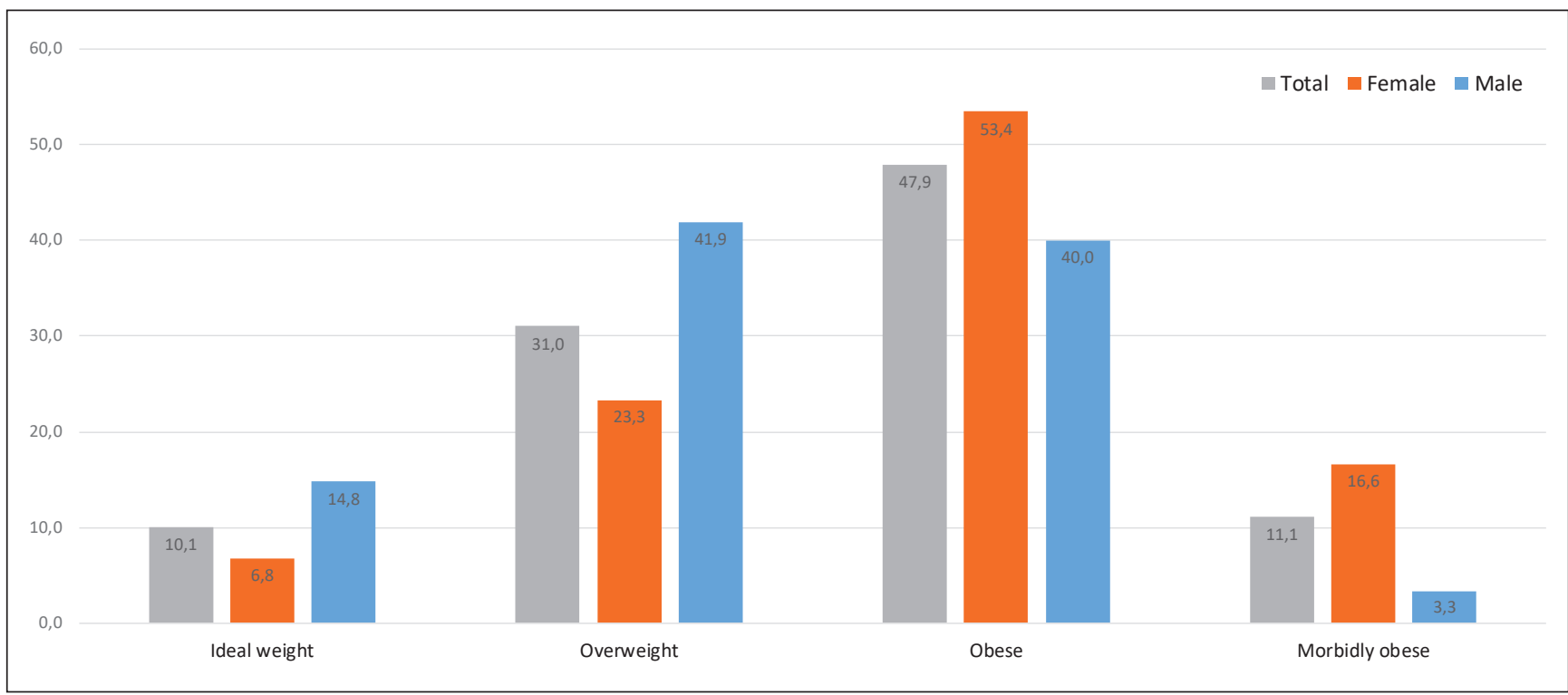

Fig. 1. Distribution of patients with type 2 diabetes according to gender and BMI categories.

home, an average office BP $>140 / 90 \mathrm{~mm} \mathrm{Hg}$ in two different visits was defined as hypertension. Dyslipidemia was TG $>150$ or LDL-C $>100$, or low HDL-C (men $<40$, women $<50 \mathrm{mg}$ / $\mathrm{dL}$ ), or receiving medications for dyslipidemia. The definitions for BMI values were: normal, 18.5-24.9 mg/dL; overweight, 25-29.9 mg/dL; moderate obesity, 30-39.9 mg/dL; severe obesity, $\geq 40 \mathrm{mg} / \mathrm{dL}$ [13]. Treatment targets were defined as HbA1c $<7 \%$, home ABP $<135 / 85$ $\mathrm{mm} \mathrm{Hg}$, and LDL-C $<100 \mathrm{mg} / \mathrm{dL}[14,15]$. Regular exercise was defined as performing physical activity on more than 2 days a week, with each episode lasting for more than 30 min. Hypoglycemia was defined according to the patients' disclosure of having classic adrenergic symptoms associated with a measured capillary glucose level of $70 \mathrm{mg} / \mathrm{dL}$ or less. Low income was self-reported monthly earnings below the minimum wage level declared in 2017. A low education level was defined as receiving less than 8 years of formal education. Macrovascular complications were either self-reported, having a history of coronary artery disease, angina, heart attack, cerebrovascular event, or peripheral artery disease, or recorded by the physicians according to findings such as non-palpable extremity pulses, low ankle-brachial index values $(\leq 0.9)$, positive findings on coronary or peripheral arteriography, and carotid or peripheral arterial duplex ultrasound examination. Retinopathy was self-reported by the patients when asked whether they have been told in eye examinations that they have any problem related to diabetes mellitus. Nephropathy was defined as the presence of albuminuria or decreased eGFR. Neuropathy was defined as the presence of symptoms related to bilateral distal symmetrical neuropathy or other autonomous neuropathies attributed to diabetes mellitus.

\section{Statistical Analysis}

Statistical analysis was performed in SPSS 18.0 (SPSS Inc., Chicago, IL, USA). Data are presented as the mean (standard deviation) for continuous variables or as number (percentage) for categorical variables. To search for the categorical relationship between BMI and the clinical, sociodemographic, and biochemical variables, patients were allocated into categories based on their BMI. 
Sonmez et al.: Obesity and the Metabolic Control of Type 2 Diabetes: TEMD Obesity Study

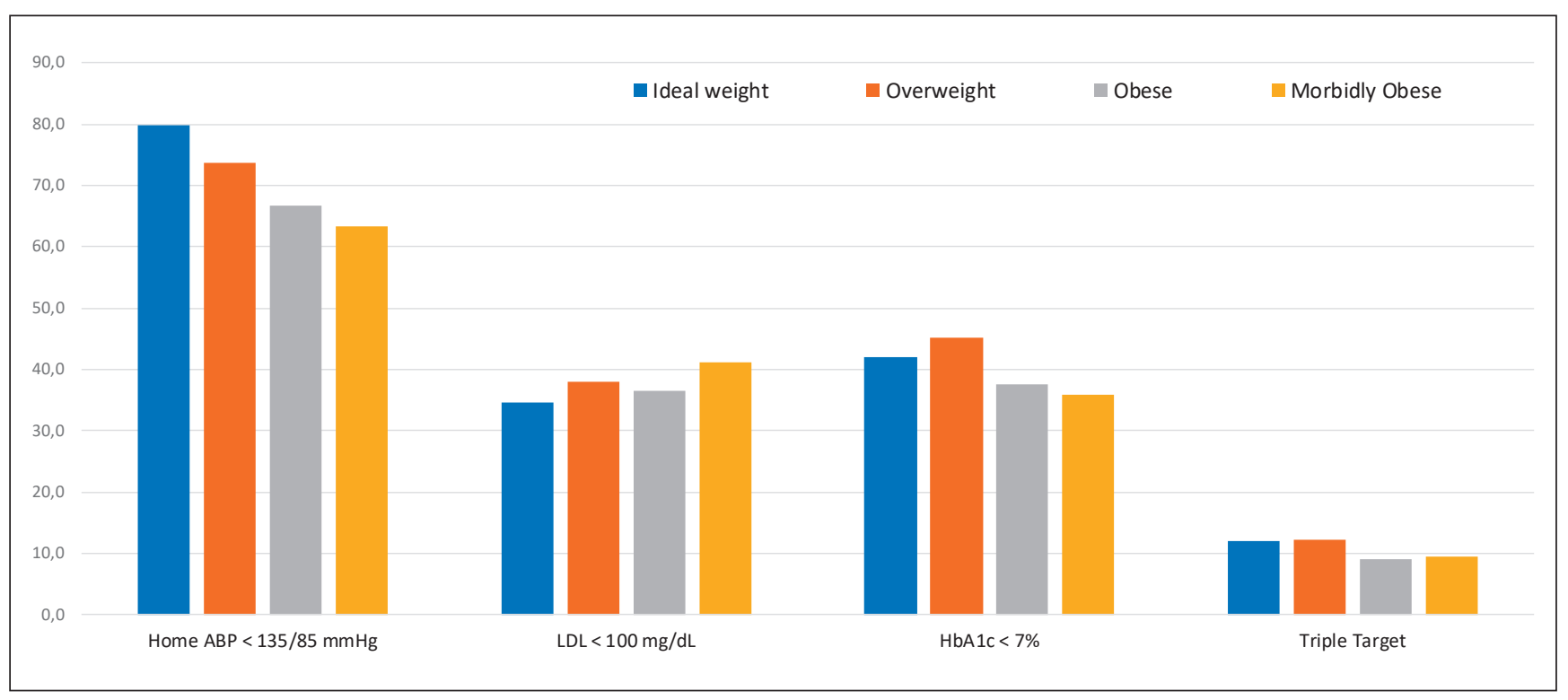

Fig. 2. Achievement of metabolic targets according to the BMI categories.

Independent-sample $t$ tests were used for comparisons among continuous variables, and $\chi^{2}$ test was employed for categorical variables. Binominal logistic regression was performed to ascertain the association between different variables and the presence of obesity. Having statistical significance $(p<0.05)$ in univariate analysis as well as the clinical rationale for a potential association with glycemic control were the criteria for inclusion in the model for these variables, which were sex, age ( $<65$ years vs. older), BMI ( $<25$ vs. $25-29.9$ vs. $\geq 30$ ), BP $(<135 / 85 \mathrm{~mm}$ Hg vs. higher), having microvascular and macrovascular complications, hypoglycemia, smoking, exercise ( $\leq 2$ /week vs. higher), statin treatment, insulin use, education level, being followed up by a private center (vs. government hospital), and monthly income (in 3 categories). Odds ratios (ORs) with 95\% confidence intervals (CI) are given in Figure 3. The $p$ value was two-tailed with a significance level of 0.05 .

\section{Results}

The baseline characteristics of patients $(n=4,648)$ stratified by their BMI categories are given in Table 1. Only 10.1\% $(n=468)$ of these patients had a normal weight. The prevalence of overweight patients is $31.0 \%(n=1,439)$, of obesity is $47.9 \%(n=2,225)$, and of severe obesity is $11.1 \%(n=516$; Table 1$)$. Both obesity (53.4 vs. $40.0 \%)$ and severe obesity (16.6 vs. $3.3 \%)$ are much more prevalent in female patients with type 2 diabetes $(p<0.001$ for both; Fig. 1). Patients in the higher BMI categories are significantly younger, with a female preponderance and lower education levels ( $p<0.001$ for all). Fewer patients achieved ABP and HbA1c goals in the higher BMI categories ( $p<0.001$ for both; Table 1; Fig. 2). Patients have higher TG and lower HDL-C levels ( $p<0.001$ for both) and much more frequently use insulin and antihypertensive drugs ( $p<0.001$ for both) in higher BMI categories. There was no significant difference between the number of patients taking statins and oral antidiabetic drugs. Microvascular complications significantly increase in patients with the higher BMI categories $(p=0.001)$, while there were no significant differences in the macrovascular complications 
Sonmez et al.: Obesity and the Metabolic Control of Type 2 Diabetes: TEMD Obesity Study

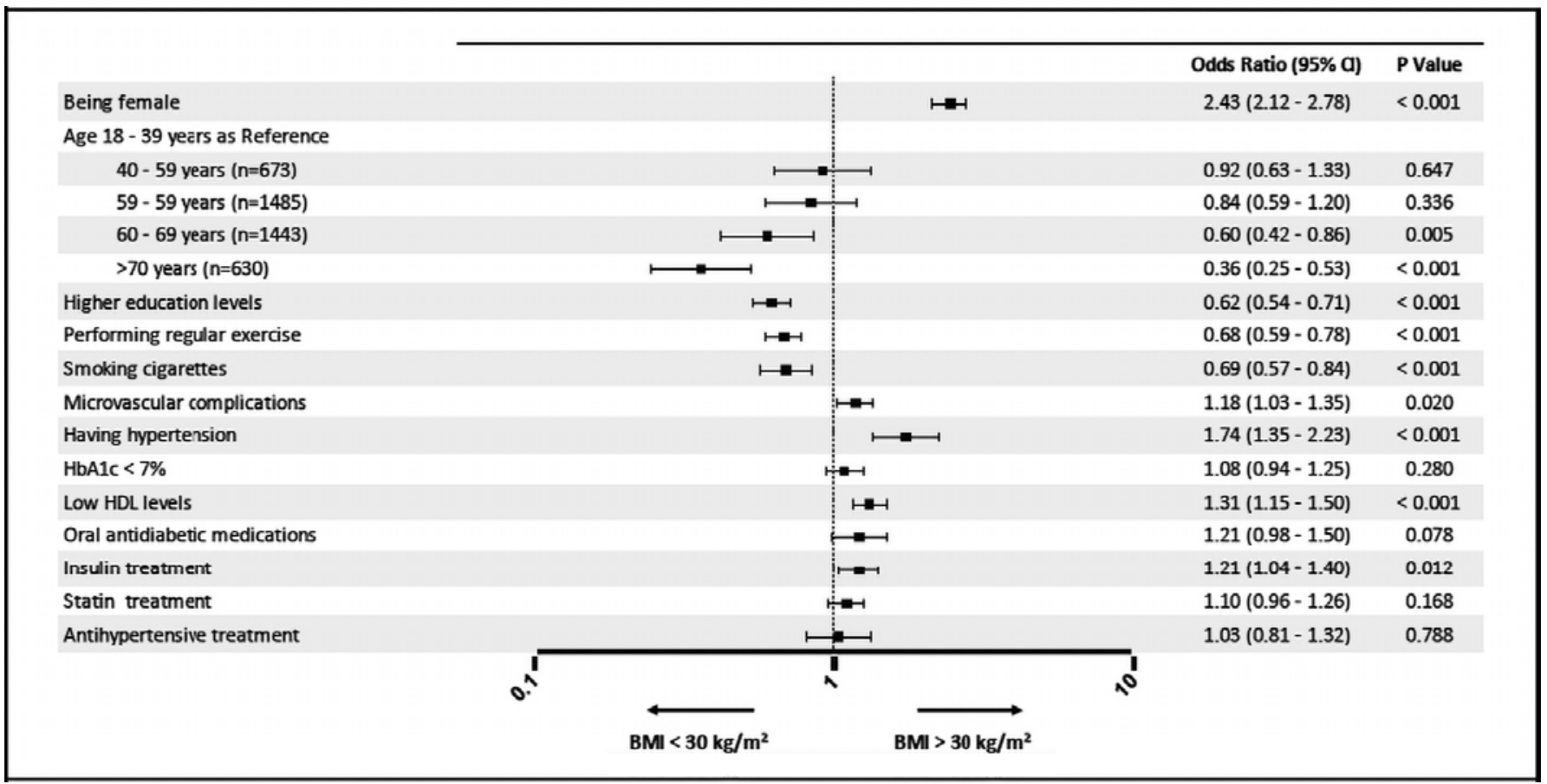

Fig. 3. The independent associates of being a patient with type 2 diabetes and obesity.

(Table 1). Considering that the percentage of female patients tends to increase with increasing BMI levels, we also compared the metabolic parameters between men and women in the different BMI categories. This comparison showed that the significant alterations of age, $\mathrm{HbA1c}, \mathrm{ABP}$, and the intake of insulin and antihypertensive drugs presented in Table 1 are not confounded by the gender differences of the patients (Table 2).

Multivariate analyses were conducted to identify the variables associated with obesity (Fig. 3). According to the results, being female (OR 2.43, 95\% CI 2.12-2.78, $p<0.001$ ), or older (OR $0.60,95 \%$ CI $0.42-0.86, p=0.005$ for ages $60-69$ years; OR $0.36,95 \%$ CI $0.25-0.53, p<$ 0.001 for age $>70$ years), having higher education levels (OR $0.62,95 \%$ CI $0.54-0.71, p<$ 0.001 ), performing exercise (OR 0.68, 95\% CI 0.59-0.78, $p<0.001$ ), smoking (OR 0.69, 95\% CI $0.57-0.84, p<0.001$ ), having microvascular complications (OR 1.18, 95\% CI 1.03-1.35, $p=0.020$ ), hypertension (OR 1.74, 95\% CI 1.35-2.23, $p<0.001$ ), and low HDL-C levels (OR $1.31,95 \%$ CI $1.15-1.50, p<0.001$ ) are the independent associates of obesity in patients with type 2 diabetes (Fig. 3).

\section{Discussion}

The TEMD Obesity Study showed that $90 \%$ of Turkish adult patients with type 2 diabetes are overweight or obese. The prevalence of obesity in patients with type 2 diabetes in this study (59\%) is considerably higher than the prevalence reported for the Turkish adult population (32\%) [16]. The situation is even worse in women. Only $6.7 \%$ of Turkish women with type 2 diabetes have a normal weight, while $17 \%$ of them have severe obesity. TEMD patients with obesity take more medications yet have poorer ABP, lipid and glucose control, and a higher prevalence of microvascular complications. Obese patients are younger and less educated. Fewer of them perform exercise and smoke than non-obese patients with type 2 


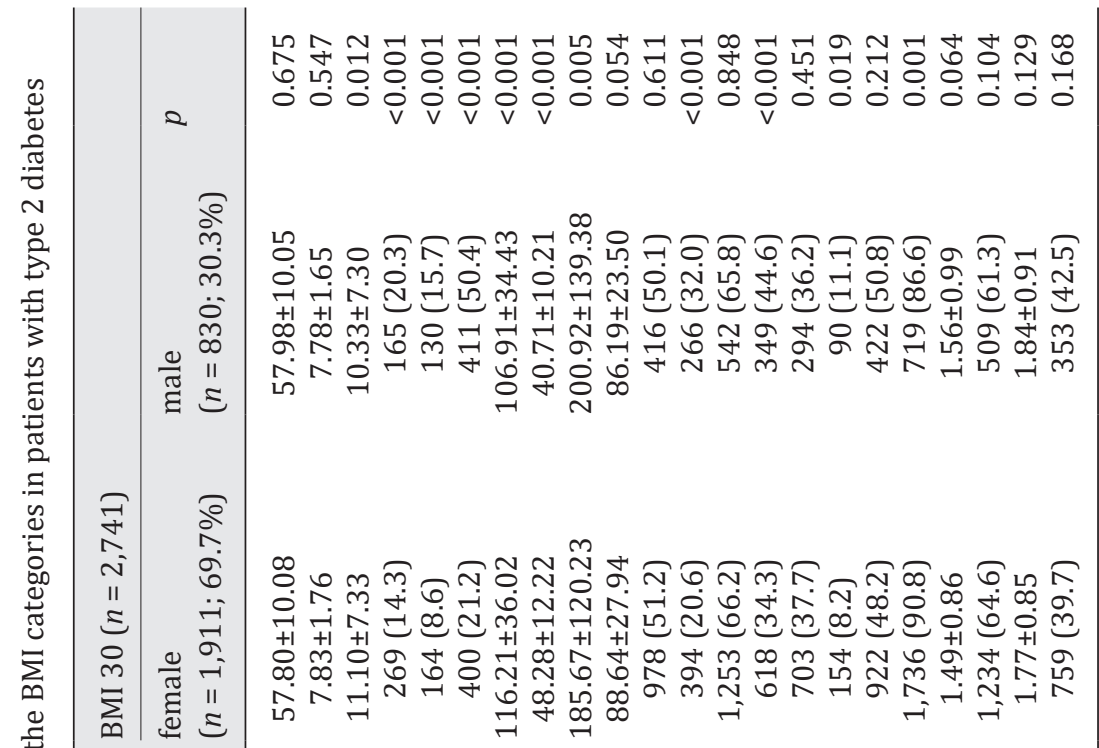

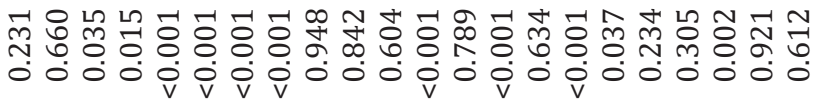

2

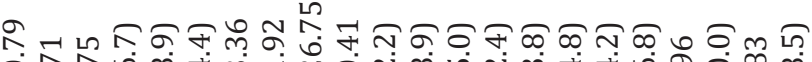

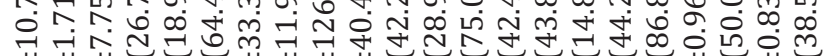

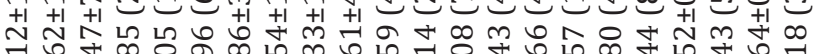

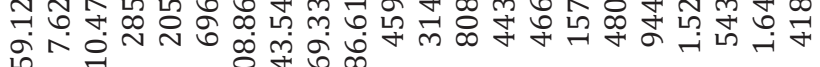
$+\rightarrow+\infty$

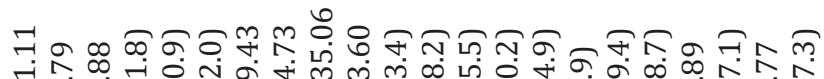

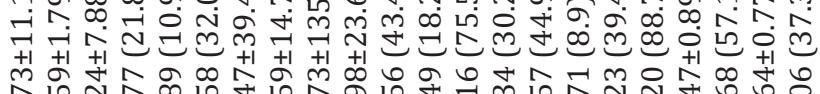

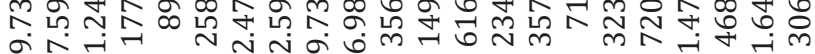
ถิ근

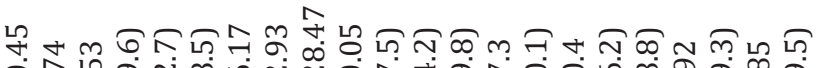

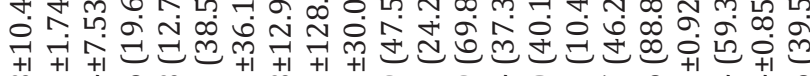
+1 +1 +1

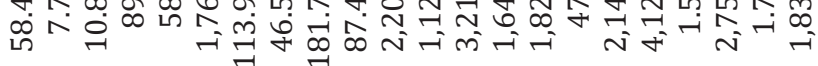

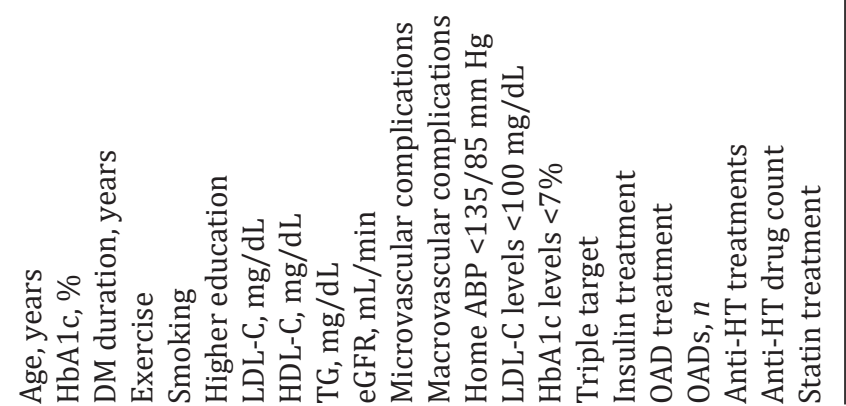


Sonmez et al.: Obesity and the Metabolic Control of Type 2 Diabetes: TEMD Obesity Study

diabetes. The independent associates of being a patient with obesity and type 2 diabetes are female gender, older age, lower education levels, a sedentary lifestyle, not smoking, taking insulin, and having hypertension, microvascular complications, and low HDL-C levels.

The worldwide frequency of overweight and obesity is rising. The prevalence varies in different geographical regions, ranging from $22 \%$ in South Asia to nearly $70 \%$ in North America $[17,18]$. Several regional and demographical factors affect the interaction between obesity and type 2 diabetes $[5,19]$. Unfortunately, Turkey has the highest prevalence of obesity and type 2 diabetes in Europe [20,21]. Characterizing the sociodemographic features of patients with type 2 diabetes and obesity will help to better understand the issue in Turkey. Large multinational studies report the prevalence of obesity as $53-62 \%$ in patients with type 2 diabetes $[10,22,23]$. The TEMD Obesity Study shows that Turkey is among the countries with the highest prevalence of obesity in patients with type 2 diabetes. The previous nationwide TURDEP study reported a $75 \%$ prevalence of overweight and obesity in the Turkish adult population [16]. According to the present TEMD Obesity Study, the prevalence is about $90 \%$ in Turkish patients with type 2 diabetes. Women with type 2 diabetes have a 2.5 times greater risk of obesity than men and have a $16.5 \%$ prevalence of severe obesity. With these numbers, Turkish women with type 2 diabetes appear to have the highest risk of obesity when compared to other studies from different regions of the world [10,22, 24-26]. Obesity is already a significant problem in nondiabetic Turkish women as well [16]. It appears that women should be the focus of nationwide measures to prevent obesity, type 2 diabetes, and associates.

The TEMD Obesity Study also shows that obese patients are significantly younger than non-obese patients. This is most likely due to the survivor bias. Obese patients have a greater likelihood of dying than those with a lower BMI $[10,25]$. Another significant aspect of TEMD patients with obesity is the low smoking prevalence. Smoking and body weight is inversely related $[27,28]$, probably due to the reduction in food intake and increased metabolic rate in smokers [29]. Weight gain after smoking cessation is well reported [10,30]. Still, the effect of smoking on mortality and morbidity is much higher than the effect of obesity [31,32], notwithstanding being an independent risk factor for type 2 diabetes [33].

TEMD patients with obesity have poorer glucose and ABP control rates, though they take more antidiabetic and antihypertensive medications. The number of patients under statin treatment is not different between the groups or the LDL-C levels. However, patients with obesity have much higher TG and lower HDL-C levels, namely atherogenic dyslipidemia. These are the expected lipid profiles in patients with obesity resulting from insulin resistance [34]. Overall, these metabolic disadvantages of Turkish patients with type 2 diabetes and obesity are similar to those populations from the different geographical regions of the world $[10,23$, $35,36]$. Randomized controlled studies show that a significant proportion of patients with type 2 diabetes cannot reach prespecified targets for the major modifiable cardiovascular risk factors [37]. The TEMD Obesity Study once again shows that obesity significantly worsens the gap between metabolic goals and achievement rates, despite more intensive treatment.

The TEMD Obesity Study may have several limitations. As it is a cross-sectional survey, we cannot interpret these findings as direct evidence of a causal relationship between obesity and increased cardiovascular risk in type 2 diabetes. However, the results are consistent with previous longitudinal studies mentioning obesity as a risk factor for type 2 diabetes and its complications $[2,38]$. Also, in the study, the micro- and macrovascular complications were mostly self-reported. This is a potential weakness for presenting the exact frequency of complications. Another limitation is that our study has the possibility of selection bias. The data may not entirely reflect the general population with type 2 diabetes. All of these patients are under follow-up in the tertiary endocrine or diabetes units. Therefore, they are more likely to have multiple comorbidities. However, the strength of the TEMD Obesity Study is the recruitment of a large number of patients representing the overall country. 
Sonmez et al.: Obesity and the Metabolic Control of Type 2 Diabetes: TEMD Obesity Study

In conclusion, this study presents a high prevalence of obesity, including severe obesity in patients with type 2 diabetes, and suggests that obesity worsens glycemic control and increases cardiovascular risk. Also, this study shows that the burden of obesity is much higher in some patients with specific sociodemographic and clinical characteristics. These findings highlight the priorities for the management of obesity in a population with the highest prevalence of obesity in Europe. Better metabolic and glycemic control rates in lean patients indicate that obesity care deserves much more attention and greater resources in the management of patients with diabetes mellitus.

\section{Acknowledgments}

The authors acknowledge all the physicians and nurses at each of the TEMD study centers participating in patient recruitment and characterization as the collaborators of the TEMD Obesity Study (see online suppl. data; see www.karger.com/doi/10.1159/000496624 for all online suppl. material).

\section{Statement of Ethics}

This study was approved by local and central ethics committees. All patients signed informed consent forms prior to data collection.

\section{Disclosure Statement}

The authors declare no duality of interest within the context of this paper.

\section{Funding Sources}

The TEMD Obesity Study was funded by the Turkish Society of Endocrinology and Metabolism. Automated BP monitors were provided by Sanovel A/S. The funding agencies had no role in the design and conduct of the study, the collection, management, analysis, and interpretation of the data, or the preparation, review, or approval of the manuscript.

\section{Author Contributions}

A.S. was the principal investigator of the study and responsible for study design and manuscript preparation. F.B., I.S., and T.S. participated in the study design and assignment of the health centers. C.H. and I.D. participated in manuscript preparation. S.K., S.G., G.O., B.O.S., S.B., F.K., F.K.K., O.D., and B.C. participated in the acquisition of the data revisions. V.Y. and I.S. were the senior advisors and made critical revisions to the manuscript. C.B. was responsible for the design and statistical analyses. A.S., T.S., F.B., and I.S. are the guarantors of this work and, as such, had full access to all the data in the study and took responsibility for the integrity of the data and the accuracy of the data analysis. 
Sonmez et al.: Obesity and the Metabolic Control of Type 2 Diabetes: TEMD Obesity Study

\section{References}

1 Langenberg C, Sharp SJ, Schulze MB, Rolandsson O, Overvad K, Forouhi NG, et al.; InterAct Consortium. Longterm risk of incident type 2 diabetes and measures of overall and regional obesity: the EPIC-InterAct casecohort study. PLoS Med. 2012;9(6):e1001230.

2 Mamtani M, Kulkarni H, Dyer TD, Almasy L, Mahaney MC, Duggirala R, et al. Waist circumference independently associates with the risk of insulin resistance and type 2 diabetes in Mexican American families. PLoS One. 2013;8(3):e59153.

3 Verma S, Hussain ME. Obesity and diabetes: an update. Diabetes Metab Syndr. 2017 Jan - Mar;11(1):73-9.

4 Joshi AV, Day D, Lubowski TJ, Ambegaonkar A. Relationship between obesity and cardiovascular risk factors: findings from a multi-state screening project in the United States. Curr Med Res Opin. 2005 Nov;21(11):175561.

5 Bovet P, Chiolero A, Gedeon J. Health effects of overweight and obesity in 195 countries. N Engl J Med. 2017 Oct;377(15):1495-7.

6 Hurren KM, Dunham MW. Understanding the impact of commonly utilized, non-insulin, glucose-lowering drugs on body weight in patients with type 2 diabetes. Expert Opin Pharmacother. 2018 Jul;19(10):1087-95.

7 Lau DC, Teoh H. Impact of current and emerging glucose-lowering drugs on body weight in type 2 diabetes. Can J Diabetes. 2015 Dec;39 Suppl 5:S148-54.

8 Domecq JP, Prutsky G, Leppin A, Sonbol MB, Altayar O, Undavalli C, et al. Clinical review: Drugs commonly associated with weight change: a systematic review and meta-analysis. J Clin Endocrinol Metab. 2015 Feb; 100(2):363-70.

9 Bhan V, Yan RT, Leiter LA, Fitchett DH, Langer A, Lonn E, et al.; Guidelines Oriented Approach in Lipid Lowering (GOALL) Registry and Vascular Protection (VP) Registry Investigators. Relation between obesity and the attainment of optimal blood pressure and lipid targets in high vascular risk outpatients. Am J Cardiol. 2010 Nov;106(9):1270-6.

10 Masmiquel L, Leiter LA, Vidal J, Bain S, Petrie J, Franek E, et al. LEADER 5: prevalence and cardiometabolic impact of obesity in cardiovascular high-risk patients with type 2 diabetes mellitus: baseline global data from the LEADER trial. Cardiovasc Diabetol. 2016 Feb;15(1):29.

11 Sonmez A, Haymana C, Bayram F, Salman S, Dizdar OS, Gurkan E, et al.; TEMD Study Group. Turkish nationwide survEy of glycemic and other Metabolic parameters of patients with Diabetes mellitus (TEMD study). Diabetes Res Clin Pract. 2018 Dec;146(Sep):138-47.

12 Friedewald WT, Levy RI, Fredrickson DS. Estimation of the concentration of low-density lipoprotein cholesterol in plasma, without use of the preparative ultracentrifuge. Clin Chem. 1972 Jun;18(6):499-502.

13 WHO. Obesity: preventing and managing the global epidemic. Report of a WHO consultation. Geneva: WHO; 2000.

14 Satman I, Imamoglu S, Yılmaz C, Akalın S, Salman S, Dinccag N, et al. Diabetes Mellitus ve Komplikasyonlarının Tanı, Tedavi ve İzlem Kılavuzu - 2017. Ankara: Bayt Matbaacılık; 2017.

15 American Diabetes Association. Introduction: standards of medical care in diabetes - 2018. Diabetes Care. 2018 Jan;41 Suppl 1:S1-2.

16 Satman I, Omer B, Tutuncu Y, Kalaca S, Gedik S, Dinccag N, et al.; TURDEP-II Study Group. Twelve-year trends in the prevalence and risk factors of diabetes and prediabetes in Turkish adults. Eur J Epidemiol. 2013 Feb; 28(2):169-80.

17 Ng M, Fleming T, Robinson M, Thomson B, Graetz N, Margono C, et al. Global, regional, and national prevalence of overweight and obesity in children and adults during 1980-2013: a systematic analysis for the Global Burden of Disease Study 2013. Lancet. 2014 Aug;384(9945):766-81.

18 Abarca-Gómez L, Abdeen ZA, Hamid ZA, Abu-Rmeileh NM, Acosta-Cazares B, Acuin C, et al.; NCD Risk Factor Collaboration (NCD-RisC). Worldwide trends in body-mass index, underweight, overweight, and obesity from 1975 to 2016: a pooled analysis of 2416 population-based measurement studies in 128.9 million children, adolescents, and adults. Lancet. 2017 Dec;390(10113):2627-42.

19 Ma RC, Chan JC. Type 2 diabetes in East Asians: similarities and differences with populations in Europe and the United States. Ann N Y Acad Sci. 2013 Apr;1281(1):64-91.

20 WHO. European health report 2018: more than numbers - evidence for all (2018) [Internet]. 2002 Aug 29. Available from: http://www.euro.who.int/en/publications/abstracts/european-health-report-2018.-morethan-numbers-evidence-for-all-2018.

21 International Diabetes Federation. IDF Diabetes Atlas. 8th ed. Brussels, Belgium: International Diabetes Federation; 2017.

22 Albu JB, Lu J, Mooradian AD, Krone RJ, Nesto RW, Porter MH, et al.; BARI 2D Study Group. Relationships of obesity and fat distribution with atherothrombotic risk factors: baseline results from the Bypass Angioplasty Revascularization Investigation 2 Diabetes (BARI 2D) trial. Obesity (Silver Spring). 2010 May;18(5):1046-54.

23 Scirica BM, Bhatt DL, Braunwald E, Steg PG, Davidson J, Hirshberg B, et al.; SAVOR-TIMI 53 Steering Committee and Investigators. Saxagliptin and cardiovascular outcomes in patients with type 2 diabetes mellitus. N Engl J Med. 2013 Oct;369(14):1317-26.

24 Wang S, Ma W, Yuan Z, Wang SM, Yi X, Jia H, et al. Association between obesity indices and type 2 diabetes mellitus among middle-aged and elderly people in Jinan, China: a cross-sectional study. BMJ Open. 2016 Nov; 6(11):e012742-9. 
Sonmez et al.: Obesity and the Metabolic Control of Type 2 Diabetes: TEMD Obesity Study

25 Miyazawa I, Kadota A, Miura K, Okamoto M, Nakamura T, Ikai T, et al. Twelve-year trends of increasing overweight and obesity in patients with diabetes: the Shiga Diabetes Clinical Survey. Endocr J. 2018 May;65(5):527-36.

26 Daousi C, Casson IF, Gill GV, MacFarlane IA, Wilding JP, Pinkney JH. Prevalence of obesity in type 2 diabetes in secondary care: association with cardiovascular risk factors. Postgrad Med J. 2006 Apr;82(966):280-4.

27 Sneve M, Jorde R. Cross-sectional study on the relationship between body mass index and smoking, and longitudinal changes in body mass index in relation to change in smoking status: the Tromso Study. Scand J Public Health. 2008 Jun;36(4):397-407.

28 Wang Q. Smoking and body weight: evidence from China health and nutrition survey. BMC Public Health. 2015 Dec;15(1):1238.

29 Dallosso HM, James WP. The role of smoking in the regulation of energy balance [Internet]. Int J Obes. 1984; 8(4):365-75.

30 Williamson DF, Madans J, Anda RF, Kleinman JC, Giovino GA, Byers T. Smoking cessation and severity of weight gain in a national cohort. N Engl J Med. 1991 Mar;324(11):739-45.

31 Wannamethee G, Shaper AG. Body weight and mortality in middle aged British men: impact of smoking [Internet]. BMJ. 1989 Dec;299(6714):1497-502.

32 Willett WC, Green A, Stampfer MJ, Speizer FE, Colditz GA, Rosner B, et al. Relative and absolute excess risks of coronary heart disease among women who smoke cigarettes. N Engl J Med. 1987 Nov;317(21):1303-9.

33 Willi C, Bodenmann P, Ghali WA, Faris PD, Cornuz J. Active smoking and the risk of type 2 diabetes: a systematic review and meta-analysis. JAMA. 2007 Dec;298(22):2654-64.

34 Klop B, Elte JW, Cabezas MC. Dyslipidemia in obesity: mechanisms and potential targets. Nutrients. 2013 Apr; 5(4):1218-40.

35 Molenaar EA, Hwang SJ, Vasan RS, Grobbee DE, Meigs JB, D’Agostino RB Sr, et al. Burden and rates of treatment and control of cardiovascular disease risk factors in obesity: the Framingham Heart Study. Diabetes Care. 2008 Jul;31(7):1367-72.

36 Li P, Chen K, Nie Y, Guo LL, Wang HB, Wang SS, et al.; DYSIS-China Study Investigators. Association of obesity with glucose, blood pressure, and lipid goals attainment in patients with concomitant diabetes and hypertension. Curr Med Res Opin. 2015;31(9):1623-31.

37 Farkouh ME, Boden WE, Bittner V, Muratov V, Hartigan P, Ogdie M, et al. Risk factor control for coronary artery disease secondary prevention in large randomized trials. J Am Coll Cardiol. 2013 Apr;61(15):1607-15.

38 Wilson PW, D'Agostino RB, Sullivan L, Parise H, Kannel WB. Overweight and obesity as determinants of cardiovascular risk: the Framingham experience. Arch Intern Med. 2002 Sep;162(16):1867-72. 